\title{
Personalized and Generalized Comparisons: Causes and Consequences of Variations in the Focus of Social Comparisons
}

\author{
Kenneth D. Locke \\ University of Idaho
}

When people compare with another person they can focus on how they compare either with just that target (a personalized comparison) or with others more generally (a generalized comparison). Four studies (two eventcontingent diary studies, one study of comparisons during a triathlon, and one controlled experiment) showed that personalized comparisons were more likely when the target's attribute was distinctive or there was an interaction or a close or emotional relationship with the target. Perhaps because these conditions that increase interest in the target as a distinct individual were less common during the triathlon than in everyday life, personalized comparisons were relatively uncommon during the triathlon but relatively common in everyday life. Across studies, generalized comparisons magnified the impact of upward comparisons on overall feelings (but not on interpersonal feelings about the self-target relationship), presumably because generalizing broadens the implications of comparisons, whereas personalizing restricts their relevance to the self-target relationship.

Keywords: social comparison; personalized; generalized; naturalistic; interpersonal

Social comparison involves juxtaposing information Sabout the self with relevant information about other target individuals (Wood, 1996). Many factors shape social comparison experiences. Probably the most important (and certainly the most studied) factor is comparison direction. Traditionally, direction has referred to vertical directions: upward (when the target is superior to the self) and downward (when the target is inferior). Recent research suggests that comparisons also can go in horizontal directions, that is, they can be experienced as connective (when self and target are similar) or contrastive (when self and target differ without either being superior; Locke, 2003, 2005). Other important factors include related attributes (such as prior experiences or current impediments) that explain the observed similarities and differences (Wood, 1989) as well as the perceived importance and permanence of those similarities and differences (Major, Testa, \& Bylsma, 1991).

The current article suggests that another factor shaping social comparison experiences is whether the scope or focus of the comparison is personal or general. The focus of some comparisons is "How do I compare particularly with this one target person?" I call these personalized comparisons. Examples of personalized comparisons are comparisons focused on questions such as, "Am I prettier than that woman John is with?" and "Does Sarah like the music I like?" The focus of other comparisons is "How do I compare generally with some set of others (of which the target is just an example)?" I call these generalized comparisons. Examples of generalized comparisons are comparisons focused on questions such as, "Am I prettier than average?" or "Do other students like the music I like?"

When making generalized social comparisons, an informative target is any target representative of the population of interest. For example, if the population of

Author's Note: I am grateful to Gwen Mitchell, Charles Anderson, Christi Banks, Taylor Danielson, Sarah Devena, Garrett Reynolds, and Rebecca Sliman for helping me collect and enter the data. Please address correspondence to Kenneth Locke, Department of Psychology, University of Idaho, Moscow, ID 83844; e-mail: klocke@uidaho.edu.

PSPB, Vol. 33 No. 2, February 2007 213-225

DOI: $10.1177 / 0146167206293492$

(C) 2007 by the Society for Personality and Social Psychology, Inc. 
interest is "students my age," then any student my age would be an informative target. The particular target is simply a source of information that could be exchanged with an equally representative target (or with an objective or statistical information source). However, when making personalized social comparisons, the population of interest is a single person, so that one person is by definition the most informative target and cannot be exchanged with any other target (or with a more abstract form of information).

Everyday observation suggests that people often care about and focus on their standing relative to specific individuals; yet, personalized comparisons rarely have been the focus of social comparison research. On one hand, most of the social comparison literature concerns comparisons between the self and another person. On the other hand, the implicit or explicit assumption is that the main purpose of the comparison is to acquire information about the self that transcends that particular self-other relationship. This assumption is explicit in Hypotheses I and II of Festinger's (1954) original statement of social comparison theory: (I) Humans are driven to evaluate their opinions and abilities and (II) they do so by comparing with the opinions and abilities of others only to the extent that objective, nonsocial means are unavailable. In other words, what matters to people is their objective standing and so they prefer to compare with objective standards.

A number of studies have questioned the assumption that objective comparison standards are more important or more preferred. Several studies have found that people seek social performance standards in addition to, and sometimes instead of, objective standards (for a review, see Wood \& Wilson, 2003). Other studies have shown that social information can sometimes influence self-evaluations and behavior more than does objective information (Klein, 1997, 2003).

The preceding studies show that people sometimes care about their social standing more than their standing relative to objective metrics but do not show if they care more about their standing relative to some people than others. If people are simply interested in where they stand relative to people in general, then they should prefer the most typical (and thus most representative) targets. However, when given the choice of comparing with a target with whom they shared a quality that was either common or distinctive, most people chose the comparison target with whom they shared a distinctive connection (Miller, Turnbull, \& McFarland, 1988). Because people identify more strongly with others with whom they share a distinctive versus nondistinctive attribute, these results suggest that people sometimes are more interested in how they stand relative to people with whom they identify than in how they stand relative to people in general.
Similarly, if people want to know where they stand relative to groups of others-whether distinctive or notthen they should prefer information from larger rather than smaller samples of those groups. For example, if people want to know their place within a population distribution, then aggregate statistical information about the population of interest is more informative than information about a single target. Yet, at least in some situations, people weigh more heavily how they compare with one individual than how they compare on average with hundreds of individuals (Buckingham \& Alicke, 2002), suggesting that people sometimes care about their standing relative to a specific other more than their standing relative to a group.

By showing that people compare themselves to individuals as well as to collectives or averages, and that the type of target makes a difference (Alicke, Klotz, Breitenbecher, Yurak, \& Vredenburg, 1995), the preceding studies suggest the importance of distinguishing between personalized and generalized comparisons. However, the distinction between types of targets in previous studies is different from the distinction between personalized and generalized comparisons in the current research. The current research assumes that the basis of most comparisons in everyday life is not abstract or statistical group information but information about specific individuals (what she did, how he looks, and so on); however, although most comparisons start with information about specific individuals, they proceed differently depending on whether the information is personalized or generalized.

\section{Hypotheses Tested}

The current studies tested several hypotheses concerning the causes and consequences of comparisons being personalized versus generalized. First, I theorized that personalized comparisons would occur when people were aware of the target as a distinct individual and were concerned with their standing relative to that individual. I hypothesized that conditions that would increase awareness of the target as an individual and concern with the self-target relationship would include interacting with the target, noticing a distinctive feature of the target, having an ongoing or close relationship with the target, and having strong positive or negative feelings toward the target. The current studies tested whether each of these conditions increased the likelihood of personalized comparisons.

Second, evidence exists that women more than men define themselves in terms of the relationships in which they are embedded, whereas men more than women define themselves in terms of the groups or collectives in which they are embedded (Baumeister \& Sommer, 1997; 
Gabriel \& Gardner, 1999). In accord with this theory, women appear to be less threatened than are men by selfrelevant upward comparisons with close friends, whereas men are less threatened than are women by self-relevant upward comparisons with their ingroups (Cross \& Madson, 1997; Gardner, Gabriel, \& Hochschild, 2002). Based on these findings, I hypothesized that women would make more personalized comparisons and men would make more generalized comparisons.

Third, I tested whether comparison focus would moderate the emotional impact of comparisons. Naturalistic studies show postcomparison affect to be more positive following downward or connective comparisons than following upward or contrastive comparisons (Locke, 2003). Because personalized comparisons restrict the relevance of comparison information to just one relationship, whereas generalized comparisons expand the relevance of comparison information to many relationships, I hypothesized that the emotional consequences of comparison direction would be greater for generalized than personalized comparisons. A similar rationale has been proposed for why making global rather than specific attributions for negative experiences predicts hopelessness and depression (Abramson, Metalsky, \& Alloy, 1988).

Studies 1 and 3 examined whether comparison focus moderated the relationship between comparison direction and postcomparison affect. Studies 2 and 4 further distinguished between two types of postcomparison affect: overall feelings and interpersonal feelings. Previous research shows that people who make a general attribution for negative feelings report less satisfaction than people who make a specific attribution, but only with respect to overall satisfaction, not with respect to satisfaction with the domain to which the specific attribution was made (e.g., negative feelings attributed to an exam still influence academic satisfaction; Keltner, Locke \& Audrain, 1993). Using the same logic, I reasoned that generalized comparisons would have more impact than personalized comparisons on overall feelings but not on interpersonal feelings specific to the selftarget relationship.

\section{STUDY 1}

To assess naturalistic social comparisons, the study employed an event-contingent self-recording procedure (Wheeler \& Reis, 1991) that has been used by numerous social comparison studies (e.g., Wheeler \& Miyake, 1992; Wood, Michela, \& Giordano, 2000). Specifically, each time participants noticed themselves making a social comparison they completed a Social Comparison Record that asked them whether the comparison was personalized or generalized, how well they knew the target, if they had interacted with the target, how often they had compared in the past (or expected to compare in the future) with this target, what attribute they compared, and how they felt after the comparison. Although there is no way to verify the accuracy or immediacy of these records, paper-and-pencil diaries do appear to yield similar results as electronic diaries that elicit or monitor response compliance (Green, Rafaeli, Bolger, Shrout, \& Reis, 2006).

Study 1 tested two key hypotheses. First, I hypothesized that comparisons made during interactions and with others who were close or were frequent comparison targets would be more likely to be personalized (because those conditions should heighten interest in the self-target relationship). Second, I hypothesized that generalized comparisons would have more impact on postcomparison affect than personalized comparisons (because generalized comparisons have broader implications). Finally, I checked if personalized comparisons were more or less common than generalized comparisons and what were the reference groups for generalized comparisons.

\section{Method}

Participants. University of Idaho undergraduates (100 women, 30 men, $M=22.2$ years old, $S D=5.1$ years) participated for extra credit in psychology classes.

Social Comparison Record (SCR). The first six items on the SCR were multiple-choice questions. The first was "During the comparison, what was your main concern?" The response options were "How do I compare particularly with this one person?" and "How do I compare generally with some set of others (of which this person is just an example)?" Half of the participants were given these response options in the reverse order; the order of the response options did not affect any of the analysis and so will not be discussed further. If participants indicated that their main concern was how they "compare generally," then they were asked to write down the group of people with whom they were comparing ("e.g., men, biology majors, all people ... ") and whether they were a member of that group.

The second question was "With whom did you compare yourself?" The response options were "friend or close relative" and "acquaintance or stranger." The third question was "What type of social contact was involved?" The response options were "interaction" and "no interaction (just saw or thought about the person)." The fourth and fifth questions were "About how many times have you compared yourself with this person in the past?" and "About how many times do 
you expect to compare yourself with this person in the future?" The response options were never, 1-5, 6-20, 21-50, and more than 50 times. In the data analyses, responses to these two items were converted to the following ordinal scale: 0 (never), 1 (1-5), 2 (6-20), 3 (21-50), and 4 (more than 50 times).

The sixth question asked, "Into which category does what you compared best fit?" The response options were "wealth, possessions, clothes, or physical appearance" and "skills, abilities, and accomplishments" and "feelings, preferences, beliefs, or personalities." The first two categories were labeled objective attributes because they are experienced as having an objective or commonly shared basis of evaluation, that is, all else equal, people generally prefer to have than to lack skills, looks, and money. The latter category was labeled subjective attributes because the criteria for evaluating beliefs, feelings, personalities, or preferences are generally perceived to be subjective rather than objective or consensual. Previous studies employing this distinction found that subjective attributes predicted making fewer upward comparisons and generally being less concerned with who was better or worse (Locke, 2003; Locke \& Nekich, 2000).

The seventh item assessed whether the comparison was contrastive, connective, downward, or upward by having participants complete the sentence, "While comparing this characteristic I was thinking that...." The response options were "we did not share this characteristic in common," "we shared this characteristic in common," "with respect to this characteristic, I was better-off," or "with respect to this characteristic, I was worse-off." Finally, respondents rated "How were you feeling right after this social comparison?" on four bipolar $(-3$ to +3$)$ scales anchored by the following terms: sad-happy, isolated-connected, insecure-confident, and worse-better. Because they strongly correlated with each other, the scales were standardized and summed to create an overall measure of postcomparison affect (Cronbach's $\alpha=.84)$.

Procedure. Participants were given self-explanatory packets containing 15 SCRs and detailed instructions. The instructions stated, "Over the next week, each time you notice yourself talking or thinking about similarities or differences between yourself and another person or persons with respect to some characteristic, fill out one of the attached Social Comparison Record sheets.... We have given you 15 record sheets. It is fine for you to finish all 15 within a few days, and it is fine for you to not finish all 15 by the end of the seven days." The mean number of records completed per participant was 9.8 $(S D=4.1$, range $=3-15)$; the total number of usable SCRs returned was 1,280 .

\section{Results and Discussion}

Descriptive statistics. Respondents compared with friends or close relatives $55.1 \%$ of the time and with acquaintances or strangers $44.9 \%$ of the time. They compared during interactions $51.0 \%$ of the time and in the absence of interactions $48.7 \%$ of the time (and skipped this item $1.3 \%$ of the time). They compared objective attributes $64.0 \%$ of the time and subjective attributes $27.6 \%$ of the time (and marked "Other" or skipped this item $8.4 \%$ of the time). The percentage of comparisons that were downward, upward, connective, and contrastive were, respectively, $25.5 \%, 22.4 \%$, $21.7 \%$, and $30.4 \%$. Most comparison targets had been targets in the past and were expected to be targets in the future. Specifically, $30.1 \%$ of targets had never been a target before and $25.5 \%$ were not expected to be a target in the future. In contrast, $46.3 \%$ had been a target more than five times previously and $47.1 \%$ were expected to be a target more than five times in the future. Because the frequencies of past comparisons and expected future comparisons were highly correlated $(r=$ .89 ), they were averaged to yield an overall measure of target frequency.

More crucial to the current research was that respondents reported that during the comparison their main concern was "How do I compare particularly with this one person" $69.7 \%$ of the time and was "How do I compare generally ..." $30.2 \%$ of the time. Thus, personalized comparisons were more than twice as common as generalized comparisons. When respondents made a generalized comparison, they reported what was the comparison group of interest and whether they belonged to that group. Respondents reported that they were a member of the comparison group $63.6 \%$ of the time and not a member $22.7 \%$ of the time (and made no response $13.7 \%$ of the time). Thus, people were more likely to assess their standing relative to groups to which they belonged than their standing relative to groups to which they did not belong. Common comparison groups included gender (e.g., "other men") or gender in addition to some other characteristic (e.g., "women my age"; $n=112)$, people in general $(n=32)$, and members of a particular religion $(n=12)$. Several common categories were probably specific to college life: people in a particular class or major ( $n=36$, e.g., "other math majors"), members of a particular fraternity or sorority $(n=23$, e.g., "Delta Gammas"), and "other students" $(n=9)$.

Multilevel data analysis. The data were observations from multiple SCRs ("level-1 units") nested within participants ("level-2 units"). Effects of within-subjects variance in the SCR (level-1) variables and betweensubjects variance in gender (a level-2 variable) were 
analyzed by means of multilevel random coefficient modeling (Kenny, Kashy, \& Bolger, 1998; Nezlek, 2001) using the program HLM 6.0 (Bryk \& Raudenbush, 1992; Bryk, Raudenbush, \& Congdon, 2005). The categorical variables were dummy-coded as follows: gender (female $=0$, male $=1$ ), comparison focus (generalized $=0$, personalized $=1)$, the four directions $(0=$ nonoccurrence, 1 = occurrence), comparison topic (objective $=0$, subjective $=1)$, close target $($ distant $=0$, close $=1$ ), and interaction (no interaction $=0$, interaction $=1$ ). The continuous variables (i.e., target frequency and postcomparison affect) were $\mathrm{z}$-scored. The level-1 predictors were centered within subjects.

Predicting comparison focus. To examine whether situational factors predicted comparison focus, I used a multilevel analysis to regress comparison focus on the lower-level predictor variables (target closeness, target frequency, interaction context, and comparison topic). I employed the Bernoulli estimation method, which involves a logit transformation on the dichotomous outcome variable (comparison focus). Personalized comparisons were more common when comparing with close others than when comparing with distant others $(\beta=0.523, S E=0.211, p=.01)$. Specifically, the percentage of personalized comparisons was $76.3 \%$ when the target was close versus $61.7 \%$ when the target was distant. Personalized comparisons also were more common when comparing during an interaction than when comparing in the absence of an interaction $(\beta=$ $0.467, S E=0.172, p<.01)$. Specifically, the percentage of personalized comparisons was $76.1 \%$ when there was an interaction versus $63.7 \%$ in the absence of any interaction. The effects of target frequency $(\beta=0.125$, $S E=0.101)$ and comparison topic $(\beta=-0.070, S E=$ 0.085 ) were not significant.

Predicting feelings. To test whether comparison focus moderated the effects of comparison direction on postcomparison affect, I regressed affect on direction, focus, and the Direction $\times$ Focus interaction (with separate regressions for each of the four comparison directions). As in previous studies, postcomparison affect was positively related to downward and connective comparisons $(\beta s=0.821$ and 0.757, SEs $=0.127$ and $0.135)$ and negatively related to upward and contrastive comparisons $(\beta s=-1.040$ and $-0.191, S E s=0.106$ and 0.094; $p$ s < .05). However, comparison focus did not moderate these effects of comparison direction (all $p$ s $>$ .1). (Adding the upper-level predictor, participant gender, and the interactions between gender and the lower-level predictors to the preceding models yielded no significant main effects or interaction effects involving gender.)
Summary and limitations. Personalized comparisons were more common than generalized comparisons, especially when making comparisons with a close other or during an interaction. When people did make generalized comparisons, the reference group was more often one to which they belonged than one to which they did not belong. Comparison focus did not moderate the impact of comparison direction on postcomparison affect. However, Study 1 did not distinguish interpersonal feelings about the self-target relationship from overall self-evaluative feelings, a limitation that Study 2 sought to rectify.

\section{STUDY 2}

Study 2 tested four additional hypotheses about the predictors and consequences of personalized comparisons. First, research suggests that attributing current feelings to specific causes decreases their influence on global judgments but not on judgments relating to the specific events to which the feelings were attributed (Keltner et al., 1993; Schwarz \& Clore, 2003). Therefore, I hypothesized that compared to generalized comparisons, personalized comparisons-whose relevance is limited to one relationship-would have less influence on overall feelings but greater influence on interpersonal feelings specific to that one relationship.

Second, Study 2 tested whether uncommon target attributes (which presumably increase awareness of and interest in the target as a unique person) would predict a more personalized comparison focus. Third, Study 2 tested whether self-worth, the most widely studied predictor and moderator of social comparison experiences (Wheeler, 2000), would predict or moderate the effects of personalized comparisons as well. Fourth, people tend to choose targets of the same gender (e.g., Felicio \& Miller, 1994; Suls, Gaes, \& Gastorf, 1979) and with whom they share uncommon versus common attributes (Miller et al., 1988); Study 2 tested if these predictors of comparison target also would predict comparison focus.

\section{Method}

Participants. University of Idaho undergraduates (93 women, 39 men, $M=21.8$ years old, $S D=4.0$ years) participated for extra credit in psychology classes.

Self-worth measures. The Rosenberg Self-Esteem Inventory (RSEI; Rosenberg, 1965) is a widely used 10 -item self-report measure of overall self-esteem. The Center for Epidemiological Studies-Depression (CESD) scale (Radloff, 1977) is a widely used, 20-item, selfreport measure of depression. In the current sample, the 
Cronbach's $\alpha$ s for the RSEI and CESD were .91 and .89 . Because they were strongly associated $(r=-.59)$, the RSEI and the CESD (reversed-scored) were converted to z-scores and summed to yield an overall measure of self-worth.

$S C R$. The first three items were multiple-choice items. The first was "I compared myself with a ...." The response options were "male I know well," "female I know well," "male I don't know well," and "female I don't know well." The second item was "The characteristic of the other person was...." The response options were "common among the people I know," "rare among the people I know," and "neither/not sure." The third item was "During the comparison, my main concern was..." The response options were "How do I compare particularly with this one person?" and "How do I compare generally with some set of others (of which this person is just an example)?"

The remaining 16 items were answered on unipolar scales ranging from 1 (not at all) to 7 (very much). The first four items assessed comparison direction. Participants were asked, "With regard to this characteristic, to what extent was the other person ... better off than you" (upward comparison), "different from you?" (contrastive), "similar to you?" (connective), and "worse off than you?" (downward). The final 12 items assessed feelings. The first four items asked respondents, "How were you feeling with this person right after the comparison?" followed by these four scales: Confident, Connected, Distant (R), and Timid (R). The four ratings were converted to z-scores and summed, yielding a measure of interpersonal feelings (Cronbach's $\alpha=.70$ ). The final eight items asked respondents, "How were you feeling in general following the comparison?" followed by these eight scales: Calm, Good About Myself, Happy, Proud, Ashamed (R), Bad About Myself $(\mathrm{R})$, Sad (R), and Upset (R). The eight ratings were converted to $\mathrm{z}$-scores and summed, yielding a measure of overall feelings (Cronbach's $\alpha=.91$ ).

Procedure. Participants were asked to complete, in order, a packet containing the RSEI, the CESD, and 10 SCRs. Participants obtained the packets from folders on a laboratory door and upon completing the packet placed it in a slot in the laboratory door. Detailed instructions asked participants to complete an SCR "each time you notice yourself talking about or thinking about similarities and/or differences between yourself and another person or persons with respect to some characteristic" and to take "as long as you need to complete the 10 records." The time to complete the records ranged from 1 to 42 days ( $M d n=7$ days). The 132 participants returned a total of 1,307 usable SCRs.

\section{Results and Discussion}

Multilevel data analysis. I used the same type of multilevel models used in Study 1 to analyze the effects of within-subjects variance in level-1 (SCR) variables and between-subjects variance in level-2 (gender and selfworth) variables. The categorical variables were dummycoded as follows: subject gender (female $=0$, male $=1$ ), target gender (different gender $=0$, same gender $=1$ ), target closeness (unknown $=0$, known $=1$ ), attribute prevalence $($ common $=1$, rare $=-1$, neither $=0)$, and comparison focus (generalized $=0$, personalized $=1$ ). The continuous variables (comparison directions and feelings) were z-scored. The level-1 predictors were centered within subjects.

Descriptive statistics. Respondents compared with targets they knew $65.1 \%$ of the time and, in accord with previous research, with targets of the same gender $68.4 \%$ of the time. They described the target's attribute as rare $29.5 \%$ of the time, as common $41.0 \%$ of the time, and as "neither/not sure" the rest of the time. Respondents reported that during the comparison their main concern was "How do I compare particularly with this one person" $67.9 \%$ of the time and was "How do I compare generally" $32.1 \%$ of the time. Thus, as in Study 1, personalized comparisons were more than twice as common as generalized comparisons.

Predicting comparison focus. To test whether the situational variables predicted whether the comparison was personalized versus generalized, I regressed comparison focus (using, as in Study 1, the Bernoulli estimation method) on target closeness, target gender, attribute prevalence, andto test for the effects of shared distinctiveness-similarity and the Similarity $\times$ Prevalence interaction. Respondents were more likely to make personalized comparisons when comparing with known than unknown others $(\beta=$ $0.656, S E=0.147, p<.001)$; the percentage of personalized comparisons was $71.8 \%$ when the target was known versus $61.1 \%$ when the target was unknown. Respondents were less likely to make personalized comparisons when the attribute was common $(\beta=-0.626, S E=0.082$, $p<.001)$; the percentage of personalized comparisons was $80.0 \%$ when the target attribute was "rare," $73.8 \%$ when the attribute was "neither," and only $54.5 \%$ when the attribute was "common." The effects of sharing the same gender $(\beta=-0.176, S E=0.148)$, sharing the attribute $(\beta=0.048, S E=0.078)$, and the Similarity $\times$ Prevalence interaction $(\beta=-0.103, S E=0.092)$ were not significant ( $p s>.2$ ).

Predicting feelings. To test whether comparison focus moderated the effects of comparison direction on feelings, 
I regressed interpersonal and overall feelings on direction, focus, and the Direction $\times$ Focus interaction (with separate regressions for each of the four comparison directions). Interpersonal feelings were positively related to downward and connective comparisons ( $\beta$ s $=0.128$ and $0.195, S E s=0.055$ and 0.051$)$ and negatively related to upward and contrastive comparisons ( $\beta \mathrm{s}=-0.324$ and $-0.180, S E s=0.052$ and $0.059 ; p s<.05)$. Overall feelings also were related positively to downward comparisons and negatively to upward comparisons $(\beta s=0.305$ and -0.502 , SEs $=0.055$ and $0.051, p s<.001)$ but were not related to connective and contrastive comparisons ( $\beta \mathrm{s}=$ 0.071 and $-0.080, S E s=0.052$ and $0.052, p s>.1$ ). The critical variables, though, were the Direction $\times$ Focus interactions. Only the Focus $\times$ Upward interaction was significant $(\beta=0.129, S E=0.054, p<.05)$, indicating that the negative effect of upward comparisons on overall feelings was weaker when the comparison was personalized than when it was generalized. (Neither gender nor self-esteem predicted comparison focus or moderated the Focus $\times$ Direction interactions.)

Summary and limitations. Personalized comparisons were more common than generalized comparisons, especially when the comparison target was a known other or the target's attribute was not common. Shared gender and shared distinctiveness, which previous studies have found to predict comparison targets, did not predict comparison focus. Upward comparisons influenced overall feelings more when the comparison was generalized than when it was personalized. One explanation is that limiting the implications of inferiority to one self-other relationship limits its impact on overall feelings while not changing its impact on feelings about that self-other relationship.

\section{STUDY 3}

The preceding two studies sampled social comparisons broadly. Therefore, they portray what social comparisons are like on average across a variety of everyday situations but do not portray what social comparisons are like in any one situation. To complement those studies, Study 3 assessed the prevalence and correlates of personalized versus generalized comparisons within one specific situation. The situation I chose was a competitive race because it was a clearly defined, time-limited, real-world event that was likely to promote social comparisons.

\section{Method}

Participants and procedure. I asked racers registering in the 2005 Coeur d'Alene triathlon/duathlon to provide their e-mail address if they were interested in participating in a brief study. I told them that they would receive no compensation but that I was contributing $\$ 500$ to the Triathlon Fund (used to maintain local running and biking paths). On the day following the race (August 15th), I e-mailed potential participants a consent form with a hyperlink to an online questionnaire. Of the 490 adults who completed the race, 159 (68 women, 91 men) completed the online questionnaire by August 19th. (Participants who attempted to access the questionnaire after that date or who had more than two missing responses were excluded from the sample.)

Internet questionnaire. The questionnaire first asked participants their age, gender, which event (individual triathlon, individual duathlon, team triathlon, or team duathlon) they entered, and how long it took them to complete that event. Then participants received the following instructions: "Please vividly recall one time during the race on Sunday when you compared yourself (however briefly) to another racer, that is, one time you can clearly remember noticing how you were similar to or different from another racer in some way." Then they answered the following questions about that comparison: (a) "The racer with whom I compared was ...." The response options were "someone I know very well," "an acquaintance," "someone I didn't know but recognized from other events," and "a stranger"; (b) "I was primarily interested in how I compared...." The response options were "particularly with that one racer" or "generally with the other racers and that person was just a convenient example"; (c) "During the comparison I was thinking how ...." The response options were "I am better-off," "I am worse-off," "we are similar," or "we are different (neither being better nor worse)"; and (d) Finally, respondents indicated whether the comparison made them feel "defeated" (R), "energized," "motivated," "bad about myself" (R), "focused," "deflated" $(\mathrm{R})$, "weak" (R), and "good about myself" on a series of scales ranging from 0 (not at all) to 4 (very much). The eight affect items were averaged to yield an overall measure of postcomparison affect (Cronbach's $\alpha=.82$ ).

\section{Results and Discussion}

Descriptive statistics. With respect to comparison targets, $64.2 \%$ were strangers, $4.4 \%$ were "someone I didn't know but recognized from other events," $10.7 \%$ were acquaintances, and $20.8 \%$ were well-known others. With respect to comparison direction, $16.9 \%$ were downward, $23.3 \%$ were upward, $34.0 \%$ were connective, and $25.8 \%$ were contrastive. With respect to comparison focus, $73.6 \%$ were generalized and $25.2 \%$ were personalized (the remaining $1.3 \%$ were missing data). 
Of interest, these statistics differ from those reported by diary studies that sampled a wide range of situations. For example, in Studies 1 and 2, personalized comparisons were more than twice as common as generalized comparisons, whereas in the current study the opposite was true. In Study 1 (and in Locke \& Nekich, 2000), comparison targets were more often close others than acquaintances or strangers, whereas in the current study the opposite was true (probably because most racers did not know each other). In Study 1 (and in Locke, 2003, Study 3), connective comparisons were the least common direction, whereas in the current study the opposite was true, perhaps because the targets were similar athletes in a similar situation (even if the situation was competitive). In sum, the current results show how the descriptive statistics from broadly sampled diary studies may not accurately represent particular situations, such as an athletic competition.

Predicting focus, affect, and performance. To test for predictors of comparison focus, I regressed focus (coded as generalized $=0$, personalized $=1)$ on gender $(\operatorname{coded}$ as female $=0$, male $=1$ ) and target closeness (coded as stranger or "recognized" other $=-1$, acquaintance $=0$, and well-known other $=1$ ). Consistent with Studies 1 and 2 , closeness predicted personalized comparisons $(\beta=.114, S E=.042, p<.01)$ but gender $\operatorname{did}$ not $(\beta=$ $.073, S E=.069, n s)$.

Mean postcomparison affect was subjected to an analysis of variance (ANOVA), with comparison focus and comparison direction as between-subjects independent variables. There were significant effects of direction, $F(3,147)=3.02, p<.05, \eta_{\mathrm{p}}^{2}=.058$, and the Focus $\times$ Direction interaction, $F(3,147)=3.39, p<.05, \eta_{\mathrm{p}}^{2}=.065$. Table 1 shows the means for each cell. Post hoc comparisons showed that generalized upward comparisons evoked worse feelings than all other comparison experiences except personalized contrastive and personalized downward comparisons.

Finally, for exploratory purposes, I also subjected completion time (the time it took a participant to finish the race) to an ANOVA, with comparison focus and direction as between-subjects independent variables. Respondents who raced in a team duathlon or triathlon $(n=32)$ were omitted from the analysis because they reported team times. Because completing the triathlon typically took longer than completing the duathlon, I first standardized the times within each event. One effect was significant: Personalized comparisons predicted faster completion times, $F(1,123)=4.17, p<$ $.05, \eta_{\mathrm{p}}^{2}=.035$. One explanation is that focusing on a single competitor creates proximal goals (e.g., "I can pass that guy"), which enhance efficacy and performance. However, other explanations are possible, for
TABLE 1: Mean Affect Ratings as a Function of Comparison Direction and Comparison Focus During a Triathlon

\begin{tabular}{llllll}
\hline & \multicolumn{2}{c}{ Personalized } & & \multicolumn{2}{c}{ Generalized } \\
\cline { 2 - 3 } Direction & $\mathrm{M}$ & $\mathrm{SE}$ & & $\mathrm{M}$ & $\mathrm{SE}$ \\
\hline Upward & $2.09_{\mathrm{b}}$ & 0.48 & & $0.82_{\mathrm{a}}$ & 0.32 \\
Downward & $1.46_{\mathrm{ab}}$ & 0.45 & & $2.26_{\mathrm{b}}$ & 0.26 \\
Connective & $2.33_{\mathrm{b}}$ & 0.32 & & $2.38_{\mathrm{b}}$ & 0.21 \\
Contrastive & $1.79_{\mathrm{ab}}$ & 0.52 & & $2.34_{\mathrm{b}}$ & 0.18 \\
\hline
\end{tabular}

NOTE: Affect ratings were on 0 to 4 scales. Means that do not share a common subscript differ at $p<.01$ by least significant difference (LSD) tests.

example, poor performance may evoke concern about one's generalized standing.

Summary and limitations. In contrast to Studies 1 and 2, comparisons in the current study were more often generalized than personalized. In accord with Studies 1 and 2, comparison focus was related to target closeness and unrelated to gender. Generalized upward comparisons evoked worse feelings than other types of generalized comparisons or personalized upward or connective comparisons. Finally, the link between comparison focus and completion time (albeit weak and unexpected) suggests that relationships between focus and objective performance measures could be a fruitful avenue for further study.

Studies 1 to 3 share the strength of assessing naturalistic social comparisons and the weakness of lacking experimental control. For example, in Study 3, distinctive attributes and personalized comparisons may be associated either because distinctiveness stimulates personal interest in the target or because a personalized focus makes target attributes seem more distinctive. The final study used experimental manipulations to isolate the causal influences on comparison focus while controlling the comparison context, the comparison direction, and the attributes compared.

\section{STUDY 4}

To systematically and independently vary the type of target, the prevalence of the target attribute, and the comparison direction, Study 4 used the method used by numerous social comparison studies (e.g., Beach et al., 1998; Broemer \& Diehl, 2004; Desteno \& Salovey, 1996; Exline \& Lobel, 2001; Lockwood, Dolderman, Sadler, \& Gerchak, 2004; McFarland, Buehler, \& MacKay, 2001; Salovey \& Rodin, 1986; Scinta \& Gable, 2005) of having participants imagine different scenarios. Prior research using this method shows that responses to imagined comparison scenarios are similar 
TABLE 2: Comparison Focus as a Function of Target and Target Attribute in Study 4

\begin{tabular}{|c|c|c|c|c|c|c|c|c|}
\hline \multirow[b]{3}{*}{ Target } & \multicolumn{4}{|c|}{ Personalized Focus } & \multicolumn{4}{|c|}{ Generalized Focus } \\
\hline & \multicolumn{2}{|c|}{$\begin{array}{c}\text { Typical } \\
\text { Attribute }\end{array}$} & \multicolumn{2}{|c|}{$\begin{array}{l}\text { Atypical } \\
\text { Attribute }\end{array}$} & \multicolumn{2}{|c|}{$\begin{array}{c}\text { Typical } \\
\text { Attribute }\end{array}$} & \multicolumn{2}{|c|}{$\begin{array}{l}\text { Atypical } \\
\text { Attribute }\end{array}$} \\
\hline & M & SE & M & SE & M & SE & M & SE \\
\hline Neutral & 3.05 & 0.13 & 3.35 & 0.12 & 3.58 & 0.12 & 3.59 & 0.11 \\
\hline Disliked & 3.21 & 0.17 & 3.67 & 0.15 & 3.57 & 0.11 & 3.65 & 0.11 \\
\hline Liked & 3.62 & 0.12 & 3.93 & 0.10 & 3.75 & 0.10 & 3.75 & 0.11 \\
\hline
\end{tabular}

NOTE: The ratings of comparison focus were on 1 to 5 scales.

to responses to real comparison situations (Lockwood et al., 2004; McFarland et al., 2001). Because in the preceding studies comparison focus moderated the emotional consequences of vertical but not horizontal comparisons, the scenarios in Study 4 included only upward and downward comparisons.

\section{Method}

University of Idaho undergraduates $(n=69)$ participated for extra credit in psychology classes. Each participant responded to 12 scenarios, one for each cell of a 3 (liked, disliked, or neutral target) $\times 2$ (typical or atypical target attribute) $\times 2$ (upward or downward comparison) within-subjects factorial design. The scenarios were based on the scenario used by McFarland et al. (2001).

Each participant received three pages. Each page began with the following instructions:

On this page you will be asked to imagine four slightly different scenarios (and answer the same questions about each one). Please imagine the scenarios as vividly as possible and hold them in mind as you answer the questions. First, think of another student <target manipulation inserted here $>$. Write his or her initials here __ and in the other red blanks below. In all of the scenarios, imagine that you and __ are participants in a study (in which two people are run at a time) and are taking the Social Perceptiveness Test (SPT). Social Perceptiveness is the ability to "read others" or accurately judge others' personalities and intentions. The SPT is a well-validated test of this important ability and has been able to predict success in many life domains (e.g., job performance, success in forming relationships, etc.).

The target manipulation asked participants to imagine either a neutral target "whose name you know but with whom you have never spent much time and toward whom you do not have strong feelings," a liked target "whose friendship you enjoy and really value," or a disliked target "toward whom you have very negative or at least mixed feelings." Each page asked about a different target; the three targets (pages) were presented to participants in one of six different orders.

On each page below these initial instructions were four different scenarios (presented in one of four different random orders). The first sentence manipulated the typicality of the target attribute as follows: "After scoring your tests, the experimenter mentions that __'s score is <insert typical or unusual here> for a college student." The next two sentences asked participants to rate their interest in a personalized comparison ("How interested are you in how your SPT score compares with __'s?") and in a generalized comparison ("How interested are you in how your SPT score compares with that of other students in general?") on 1 (not at all) to 5 (very) scales. Next, participants learned that the comparison direction was either upward ("you got a Social Perceptiveness Test score of $68 \%$ whereas _ got a $91 \%$ ") or downward ("you got a Social Perceptiveness Test score of $91 \%$ whereas _ got a $68 \%$ "). Finally, participants rated their interpersonal feelings ("How would you feel about your SPT performance compared to __'s performance") and overall feelings ("How would you feel overall?") on -2 (very bad) to +2 (very good) scales.

\section{Results and Discussion}

Predicting comparison focus. A 3 (target: liked, disliked, or neutral) $\times 2$ (target attribute: typical or atypical) $\times 2$ (focus: personalized or generalized) withinsubjects ANOVA on ratings of comparison focus yielded significant main effects of target, $F(2,136)=9.71$, and target attribute, $F(1,68)=26.64, \eta_{\mathrm{p}}^{2} \mathrm{~s}=.26$ and .28 , $p \mathrm{~s}$ $<.01$. However, type of focus moderated the effects of both target, $F(2,136)=5.31$, and target attribute, $F(1$, $68)=24.34, \eta_{\mathrm{p}}^{2} \mathrm{~s}=.18$ and $.26, p \mathrm{~s}<.01$. Table 2 shows the means for each cell in the design. People were more interested in personalized comparisons with atypical than typical target attributes, with liked than disliked targets, and with disliked than neutral targets $(p s<.01$ by LSD tests). Target and target attribute did not influence interest in generalized comparisons (all ps > .01), which makes sense because features of the target or target attribute should not influence interest in how one stands relative to some larger group.

Predicting feelings. After learning the direction of comparison, participants reported their interpersonal and overall feelings. As usual, both interpersonal and overall feelings were higher after downward comparisons $(M \mathrm{~s}=$ 0.89 and 1.15 , SEs $=.08$ and .08$)$ than upward comparisons $(M s=-1.07$ and $-1.09, S E s=.07$ and $.08 ; p s<.01)$. To test whether comparison focus moderated these effects of direction, I regressed participants' interpersonal and overall feelings following upward and downward 
comparisons on participants' interest in personalized and generalized comparisons. In accord with the results of Studies 2 and 3, there was a marginally significant negative relationship between a generalized comparison focus and overall feelings following upward comparisons $(B=$ $-0.185, S E=.098, p=.06$ ). In contrast to the results of Studies 2 and 3, there was also a positive relationship between a personalized comparison focus and interpersonal feelings following downward comparisons $(B=$ $0.328, S E=0.100, p<.01$ ). Exploratory analyses (guided by self-evaluation maintenance model research showing that reactions to downward comparisons with specific targets depends on the relationship with the target; Beach et al., 1998; Tesser, 1988) showed that a personalized focus predicted more positive interpersonal feelings following downward comparisons with disliked targets, $r(67)=0.29, p<.05$, but not liked targets, $r(67)=.01$, $n s$. Thus, perhaps one reason a personalized focus did not enhance interpersonal feelings following downward comparisons in Studies 2 and 3 was that participants in those studies typically liked their comparison targets.

\section{GENERAL DISCUSSION}

Two event-contingent naturalistic diary studies, a survey of comparisons during an athletic competition, and a controlled laboratory experiment explored the prevalence, predictors, and effects of a social comparison being personalized (being concerned "particularly with this one person") versus generalized (being concerned "generally with some set of others"). The following discussion summarizes the findings and how they can enhance our understanding of social comparison experiences.

\section{What Predicts Comparison Focus?}

First, it is worth noting that the predictors of comparison focus differ from the predictors of comparison target. In particular, sharing the same gender (Felicio \& Miller, 1994), sharing a distinctive attribute (Miller et al., 1988), and similarity with respect to the attribute being compared (Wheeler, Koestner, \& Driver, 1982) have all been found to predict target preferences but were not found to predict comparison focus once a target was chosen. Also, despite evidence that women attend more to their standing relative to individuals and men to their standing relative to collectives (e.g., Baumeister \& Sommer, 1997; Gabriel \& Gardner, 1999; Gardner et al., 2002), the current studies found no gender differences in comparison focus.

As hypothesized, what did increase the likelihood of personalized comparisons were conditions that increased awareness of and interest in targets as distinct individuals.
For example, personalized comparisons were more likely during interactions or when the target was a close or a liked or disliked other (vs. an acquaintance or stranger that did not evoke strong feelings). Having an interaction with or a close or emotional relationship with the target presumably heightens awareness of and interest in the target as a distinct individual.

I also hypothesized that atypical target attributes would raise awareness of and interest in the target as a distinct individual, and as hypothesized, Study 2 found that people were more likely to make personalized comparisons when the target attribute was not common, and Study 4 found that people were more interested in making personalized comparisons with atypical than typical target scores. Although these effects were large, they could be explained in other ways. For example, people may have been interested in comparing their scores with atypical scores because when given feedback on a novel dimension people often initially seek to place themselves relative to the endpoints of that dimension (Wheeler et al., 1969). Thus, more research is needed to clarify the mechanism by which typical and atypical attributes influence comparison focus.

A more general limitation is that the current article gives more consideration to what promotes personalized comparisons than to what promotes generalized comparisons, but consideration of both issues is needed for a complete understanding of the determinants of comparison focus. One prediction is that people will make more generalized comparisons when their status or solidarity relative to a group matters, either because they are group members or the group can influence important outcomes. Another prediction is that people will be more open to making generalized comparisons when the target or target attribute seems typical and thus informative of standing in relation to a group; likewise, people interested in their standing in a group may seek targets whose attributes appear representative of that group.

\section{How Prevalent Are Personalized Comparisons?}

Much of the literature on social comparisons has focused on impersonal comparisons, and certainly many situations exist in which people view comparison targets solely as useful sources of information. For example, when people face unfamiliar decisions (such as whether to attempt an unfamiliar ski slope or join an unfamiliar group), they are likely to seek comparisons that yield information relevant to their decisions (Suls, Martin, \& Wheeler, 2000; Wheeler, Martin, \& Suls, 1997). In many other situations, however, rational models of target selection may fail because the comparer's interest is not rational (in terms of maximizing information) but personal. 
Consistent with previous event-contingent diary studies of naturalistic social comparison (Locke \& Nekich, 2000; Wheeler \& Miyake, 1992), Studies 1 and 2 found that most comparisons occurred with close others and approximately half occurred during interactions. Perhaps because the situations that promote a personalized focus-such as interacting with close others-were so common, Studies 1 and 2 found that personalized comparisons were more than twice as common as generalized comparisons. The opposite was true in the triathlon study: Generalized comparisons were more than twice as common as personalized comparisons. Again, the context probably explains the difference in prevalence. Known targets and interpersonal interactions promote personalized comparisons, and during the athletic competition, less than one third of the comparisons involved known targets and probably none involved face-to-face interactions.

One limitation of these self-report studies is that the sample of comparisons that participants notice and select to report may not be representative of the population of naturalistic comparisons. For example, selfreport studies may undersample comparisons that occur automatically and effortlessly (Gilbert, Giesler, \& Morris, 1995); consequently, to the extent that automatic comparisons target close others (Mussweiler \& Rüter, 2003) and close targets promote personalized comparisons, self-report studies may undersample personalized comparisons.

\section{Does Comparison Focus Moderate the Emotional Impact of Comparisons?}

Studies 2, 3, and 4 consistently found that the negative impact of upward comparisons on overall feelings was greater when the comparisons were generalized than when they were personalized (i.e., relevant to just one relationship). This finding fits with research showing that framing the causes (and thus the implications) of negative experiences in broad rather than specific terms increases their impact on global feelings and judgments (Abramson et al., 1988; Schwarz \& Clore, 2003). Studies 2, 3, and 4 also found that personalizing comparisons does not reduce their impact on interpersonal feelings. This finding fits with research showing that attributing negative experiences to a specific issue does not reduce their impact on feelings about that specific issue (Keltner et al., 1993).

Klein (2003) also found that vertical comparisons had more emotional and behavioral impact when people compared with the average of many other participants than when they compared with one other participant. However, Klein's findings and our findings highlight two different phenomena. Because the participants in
Klein's "single other" condition were comparing with a stranger with whom they had no contact, they were probably more concerned with their generalized than their personalized standing. Thus, the differences between Klein's single other and "average other" conditions reflect differences in the impact of generalized comparisons based on more versus less information (rather than differences in the impact of personalized vs. generalized comparisons).

Comparison focus did not moderate the impact of horizontal comparisons. I suspect that the implications of comparison focus are more complicated for horizontal comparisons than for vertical comparisons. One complication is that if people seek an optimal level of distinctiveness (Brewer, 1991), then generalized connective comparisons may evoke both positive feelings (feeling validated by many others) and negative feelings (feeling a loss of personal distinctiveness). In contrast, there is no optimal level of inferiority; with few exceptions, the more people who are superior to you, the worse it feels. A related issue is that generalized connective comparisons may enlarge the number of targets with which one feels connected but diffuse the intensity of those feelings; conversely, personalized connective comparisons may restrict connected feelings to one relationship but enhance the significance of those feelings ("this is about you and me, and nobody else").

\section{Future Directions}

Self-serving construals. People can frame social comparisons in ways that make them less threatening. For example, people tend to inflate upward comparison targets' abilities, presumably because thinking that superior others are extremely able protects the belief that the self is very able (Alicke, LoSchiavo, Zerbst, \& Zhang, 1997). However, comparison focus may moderate which thoughts are self-protective. For instance, imagine Jane thinks, "Sue is prettier than I am." If Jane's concern is how she compares generally with other women, then thinking, "Sue is as pretty as a supermodel" (and thus not representative) may make Jane feel better. However, if Jane's concern is how she compares specifically with Sue-who is currently flirting with Jane's boyfriendthen thinking, "Sue is as pretty as a supermodel" may make Jane feel much worse.

Subtle independent and dependent variables. To avoid demand characteristics and self-report biases, future research may employ more subtle or implicit manipulations and measures. For example, priming a relational self-construal may promote personalized comparisons, whereas priming a collective self-construal may promote generalized comparisons (e.g., Gardner et al., 
2002). If so, priming could be used to manipulate comparison focus experimentally. As another example, whether personalized versus generalized comparisons prime different information (e.g., distinctive vs. common target attributes) could be assessed by measuring the speed of subsequent judgments (e.g., Mussweiler \& Bodenhausen, 2002). Finally, there are objective performance measures, such as the completion time measure in our triathlon study, which minimize self-report biases without sacrificing real-world validity.

Beyond either/or. I have been describing comparisons as either personalized or generalized. However, comparisons can be both personalized and generalized; indeed, in Study 4, interest in personalized and generalized comparisons was positively related. A comparison that is both personalized and generalized may be able to meet multiple goals. Many theorists maintain that two basic goals of social life are status or agency and solidarity or communion (Brown, 1965; Horowitz, 2004). In the context of social comparisons, downward comparisons generally enhance status and connective comparisons generally enhance solidarity (Locke, 2003). Comparisons that are both personalized and generalized may enable people to make status-enhancing downward comparisons and solidarity-enhancing connective comparisons simultaneously. For example, people can make a personalized connective comparison and a generalized downward comparison simultaneously by thinking, "you and I share something they lack," or can make a personalized downward comparison and a generalized connective comparison simultaneously by thinking, "you lack something we have."

\section{Conclusions}

In experimental social comparison research, the targets are often anonymous strangers that the participants will never meet; consequently, the participants often treat potential targets as interchangeable sources of information. Outside the laboratory, however, the comparison targets often are known others with whom comparers have a continuing and consequential relationship and therefore are not interchangeable. Indeed, comparers may sometimes be interested in their standing relative to just one person and nobody else (e.g., "Am I better looking than that guy flirting with my girlfriend?"), in which case no other target could possibly be as informative. Thus, although there are many situations in which people want to compare themselves with objective metrics or statistical norms (e.g., the "highest possible score" or the "class average") or interchangeable exemplars of categories of people (e.g., "someone who has passed the exam"), there are other situations in which the motives are more personal and the comparisons more personalized. Moreover, by narrowing or broadening the meaning of a comparison, comparison focus can shape the implications that social comparisons have for feelings, judgments, and actions. For all of these reasons, I believe that the distinction between personalized and generalized comparisons is important for understanding of how people actually experience social comparisons in their everyday lives.

\section{REFERENCES}

Abramson, L. Y., Metalsky, G. I., \& Alloy, L. B. (1988). Hopelessness depression: A theory-based subtype of depression. Psychological Review, 96, 358-372.

Alicke, M. D., Klotz, M. L., Breitenbecher, D. L., Yurak, T. J., \& Vredenburg, D. S. (1995). Personal contact, individuation, and the better-than-average effect. Journal of Personality and Social Psychology, 68, 804-825.

Alicke, M. D., LoSchiavo, F. M., Zerbst, J., \& Zhang, S. (1997). The person who outperforms me is a genius: Maintaining perceived competence in upward social comparison. Journal of Personality and Social Psychology, 73, 781-789.

Baumeister, R. F., \& Sommer, K. L. (1997). What do men want? Gender differences and two spheres of belongingness: Comment on Cross and Madson (1997). Psychological Bulletin, 122, 38-44.

Beach, S. R. H., Tesser, A., Fincham, F. D., Jones, D. J., Johnson, D., \& Whitaker, D. J. (1998). Pleasure and pain in doing well, together: An investigation of performance-related affect in close relationships. Journal of Personality and Social Psychology, 74, 923-938.

Brewer, M. B. (1991). The social self: On being the same and different at the same time. Personality and Social Psychology Bulletin, $17,475-482$.

Broemer, P., \& Diehl, M. (2004). Romantic jealousy as a social comparison outcome: When similarity stings. Journal of Experimental Social Psychology, 40, 393-400.

Brown, R. (1965). Social psychology. New York: Free Press.

Bryk, A. S., \& Raudenbush, S. W. (1992). Hierarchical linear models: Applications and data analysis methods. Newbury Park, CA: Sage.

Bryk, A. S., Raudenbush, S. W., \& Congdon, R. T. (2005). HLM 6: Hierarchical linear and nonlinear modeling. Chicago: Scientific Software International.

Buckingham, J. T., \& Alicke, M. D. (2002). The influence of individual versus aggregate social comparison and the presence of others on self-evaluations. Journal of Personality and Social Psychology, 83, 1117-1130.

Cross, S. E., \& Madson, L. (1997). Models of the self: Self-construals and gender. Psychological Bulletin, 122, 5-37.

Desteno, D. A., \& Salovey, P. (1996). Jealousy and the characteristics of one's rival: A self-evaluation maintenance perspective. Personality and Social Psychology Bulletin, 22, 920-932.

Exline, J., \& Lobel, M. (2001). Private gain, social strain: Do relationship factors shape responses to outperformers? European Journal of Social Psychology, 31, 593-607.

Felicio, D. M., \& Miller, C. T. (1994). Social comparison in medical school: What students say about gender and similarity. Basic and Applied Social Psychology, 15, 277-296.

Festinger, L. (1954). A theory of social comparison processes. Human Relations, 7, 117-140.

Gabriel, S., \& Gardner, W. L. (1999). Are there "his" and "her" aspects of interdependence? Gender differences in collective versus relational interdependence. Journal of Personality and Social Psychology, 77, 642-655.

Gardner, W. L., Gabriel, S., \& Hochschild, L. (2002). When you and I are "we," you are not threatening: The role of self-expansion in social comparison. Journal of Personality and Social Psychology, $82,239-251$. 
Gilbert, D. T., Giesler, R. B., \& Morris, K. A. (1995). When comparisons arise. Journal of Personality and Social Psychology, 69, 227-236.

Green, A. S., Rafaeli, E., Bolger, N., Shrout, P. E., \& Reis, H. T. (2006). Paper or plastic? Data equivalence in paper and electronic diaries. Psychological Methods, 11, 87-105.

Horowitz, L. M. (2004). Interpersonal foundations of psychopathology. Washington, DC: American Psychological Association.

Keltner, D., Locke, K. D., \& Audrain, P. (1993). The influence of attributions on the relevance of negative feelings to personal satisfaction. Personality and Social Psychology Bulletin, 19, 21-29.

Kenny, D. A., Kashy, D. A., \& Bolger, N. (1998). Data analysis in social psychology. In D. T. Gilbert, S. T. Fiske, \& G. Lindzey (Eds.), The handbook of social psychology (4th ed., pp. 233-265). New York: McGraw-Hill.

Klein, W. M. (1997). Objective standards are not enough: Affective, self-evaluative, and behavioral responses to social comparison information. Journal of Personality and Social Psychology, 72, 763-774

Klein, W. M. (2003). Effects of objective feedback and "single other" or "average other" social comparison feedback on performance judgments and helping behavior. Personality and Social Psychology Bulletin, 29, 418-429.

Locke, K. D. (2003). Status and solidarity in social comparison: Agentic and communal values and vertical and horizontal directions. Journal of Personality and Social Psychology, 84, 619-631.

Locke, K. D. (2005). Connecting the horizontal dimension of social comparison with self-worth and self-confidence. Personality and Social Psychology Bulletin, 31, 795-803.

Locke, K. D., \& Nekich, J. (2000). Agency and communion in naturalistic social comparison. Personality and Social Psychology Bulletin, 26, 864-874.

Lockwood, P., Dolderman, D., Sadler, P., \& Gerchak, E. (2004). Feeling better about doing worse: Social comparisons within romantic relationships. Journal of Personality and Social Psychology, 87, 80-95.

Major, B., Testa, M., \& Bylsma, W. H. (1991). Responses to upward and downward social comparisons: The impact of esteem-relevance and perceived control. In J. Suls \& T. A. Wills (Eds.), Social comparison: Contemporary theory and research (pp. 237-260). Hillsdale, NJ: Lawrence Erlbaum.

McFarland, C., Buehler, R., \& MacKay, L. (2001). Affective responses to social comparisons with extremely close others. Social Cognition, $19,547-586$

Miller, D. T., Turnbull, W., \& McFarland, C. (1988). Particularistic and universalistic evaluation in the social comparison process. Journal of Personality and Social Psychology, 6, 908-917.

Mussweiler, T., \& Bodenhausen, G. (2002). I know you are, but what am I? Self-evaluative consequences of judging ingroup and outgroup members. Journal of Personality and Social Psychology, 82, 19-32.

Mussweiler, T., \& Rüter, K. (2003). What friends are for! The use of routine standards in social comparison. Journal of Personality and Social Psychology, 85, 467-481.

Nezlek, J. B. (2001). Multilevel random coefficient analyses of eventand interval-contingent data in social and personality psychology research. Personality and Social Psychology Bulletin, 27, 771-785.
Radloff, L. (1977). The CES-D scale: A self-report depression scale for research in the general population. Applied Psychological Measurement, 1, 385-401.

Rosenberg, M. (1965). Society and the adolescent self-image. Princeton, NJ: Princeton University Press.

Salovey, P., \& Rodin, J. (1986). The differentiation of social-comparison jealousy and romantic jealousy. Journal of Personality and Social Psychology, 50, 1100-1112.

Schwarz, N., \& Clore, G. L. (2003). Mood as information: 20 years later. Psychological Inquiry, 14, 296-303.

Scinta, A., \& Gable, S. (2005). Performance comparisons and attachment: An investigation of competitive responses in close relationships. Personal Relationships, 12, 357-372.

Suls, J., Gaes, G., \& Gastorf, J. (1979). Evaluating a sex-related ability: Comparison with same-, opposite-, and combined-sex norms. Journal of Research in Personality, 13, 294-304.

Suls, J., Martin, R., \& Wheeler, L. (2000). Three kinds of opinion comparison: The triadic model. Personality and Social Psychology Review, 4, 219-237.

Tesser, A. (1988). Toward a self-evaluation maintenance model of social behavior. In L. Berkowitz (Ed.), Advances in experimental social psychology (Vol. 21, pp. 181-222). San Diego, CA: Academic Press.

Wheeler, L. (2000). Individual differences in social comparison. In J. Suls \& L. Wheeler (Eds.), Handbook of social comparison: Theory and research (pp. 141-158). New York: Plenum.

Wheeler, L., Koestner, R., \& Driver, R. (1982). Related attributes in the choice of comparison others: It's there, but it isn't all there is. Journal of Experimental Social Psychology, 18, 489-500.

Wheeler, L., Martin, R., \& Suls, J. (1997). The proxy model of social comparison for self-assessment of ability. Personality and Social Psychology Review, 1, 54-61.

Wheeler, L., \& Miyake, K. (1992). Social comparison in everyday life. Journal of Personality and Social Psychology, 62, 760-773.

Wheeler, L., \& Reis, H. T. (1991). Self-recording of everyday life events: Origins, types, and uses. Journal of Personality, 59, 339-354.

Wheeler, L., Shaver, K. G., Jones, R. A., Goethals, G. R., Cooper, J., Robison, J., et al. (1969). Factors determining choice of a comparison other. Journal of Experimental Social Psychology, 5, 219-232.

Wood, J. V. (1989). Theory and research concerning social comparisons of personal attributes. Psychological Bulletin, 106, 231-248.

Wood, J. V. (1996). What is social comparison and how should we study it? Personality and Social Psychology Bulletin, 22, 520-537.

Wood, J. V., Michela, J. L., \& Giordano, C. (2000). Downward comparison in everyday life: Reconciling self-enhancement models with the mood-cognition priming model. Journal of Personality \& Social Psychology, 79, 563-579.

Wood, J. V., \& Wilson, A. E. (2003). How important is social comparison? In M. Leary \& J. Tangney (Eds.), Handbook of self and identity (pp. 344-366). New York: Guilford.

Received January 24, 2005

Revision accepted July 20, 2006 